\title{
COVID-19 associated spontaneous barotrauma: a literature
}

\section{review [version 1; peer review: 2 approved with reservations,}

\section{1 not approved]}

\author{
Razia Rehmani1-3, Juan Salazar2-4, Shorabh Sharma2-4, Oscar Cisneros ${ }^{2-4}$, \\ Carlos E. Arias-Morales (D2-4 \\ 1Department of Radiology, St. Barnabas Hospital, Bronx, New York, 10457, USA \\ ${ }^{2}$ City University of New York, Sophie Davis School of Biomedical Education, Bronx, New York, 10457, USA \\ ${ }^{3}$ Albert Einstein College of Medicine, Bronx, New York, 10461, USA \\ ${ }^{4}$ Department of Medicine, St. Barnabas Hospital, Bronx, New York, 10457, USA
}

V1 First published: 21 May 2021, 10:412

https://doi.org/10.12688/f1000research.52381.1

Latest published: 21 May 2021, 10:412

https://doi.org/10.12688/f1000research.52381.1

\section{Abstract}

Reports of spontaneous pneumothorax and pneumomediastinum as a complication of coronavirus disease (COVID-19) have been increasing. COVID-19 causes inflammatory disease mainly affecting the respiratory system. Severity varies from asymptomatic pulmonary findings on imaging to acute respiratory distress syndrome along with pleural effusions, consolidations and spontaneous pneumomediastinum and pneumothorax.

The aim of this paper was to review the literature to explore the association between pneumomediastinum/pneumothorax and COVID-19 respiratory disease, both in patients on ventilators and without ventilators, on a spontaneous basis. To this end, we conducted a comprehensive online literature search using PubMed for articles published with the key words of 'spontaneous pneumothorax', 'pneumomediastinum' and 'COVID-19'. Further references were obtained through cross-referencing the bibliographies cited in each publication.

We found that spontaneous barotrauma is one of the complications associated with COVID-19 infection and has been observed in patients with and without mechanical ventilation. The process of pneumomediastinum and pneumothorax development is not well understood, especially in patients without underlying lung disease or on mechanical ventilation. We identified various factors that predispose to barotrauma. First, the direct infection of the Type I and Type II pneumocytes by the virus. Second, the pressure gradient between the alveoli and the pulmonary interstitium. Finally, barotrauma can occur secondary to the severe inflammatory response from the COVID-19-related cytokine storm. These conditions are all

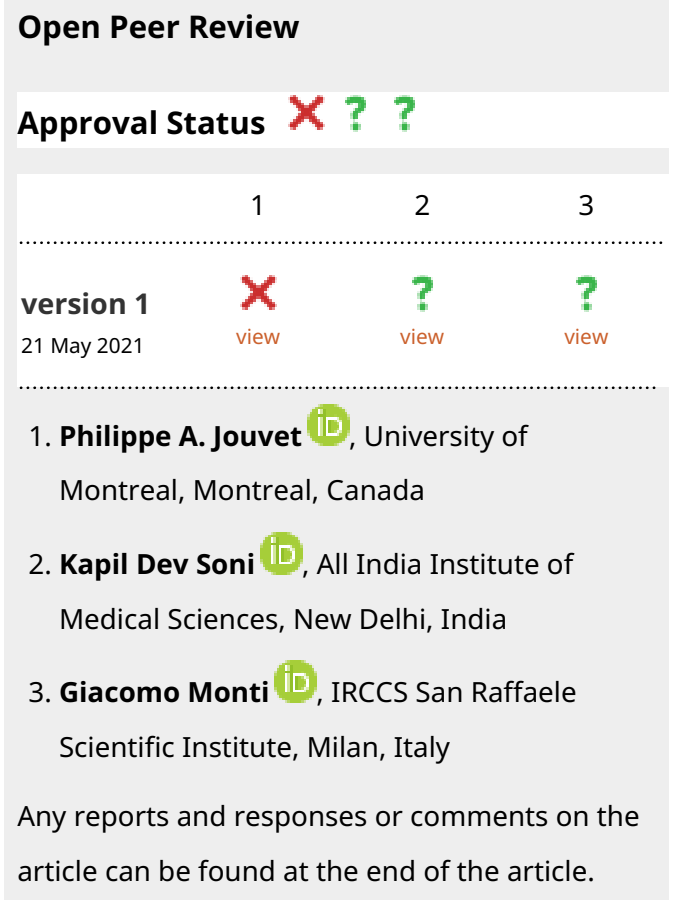


associated with severe alveolar damage and rupture of the alveolar wall that can produce pneumomediastinum and pneumothorax, both in mechanically ventilated patients and non-ventilated patients.

COVID-19 is associated complications result in prolonged mechanical ventilation and length of stay, as well as overall increase in morbidity and mortality. Spontaneous pneumothorax and pneumomediastinum are two serious complications. Education regarding the adjustment of ventilation settlings in the ventilator-dependent COVID-19 patient may perhaps offset the iatrogenic component of barotrauma seen in some such patients.

\section{Keywords}

COVID-19, Barotrauma, Pneumothorax, Pneumomediastinum

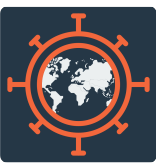

This article is included in the Emerging Diseases and Outbreaks gateway.

collection.

Corresponding author: Carlos E. Arias-Morales (carias@sbhny.org)

Author roles: Rehmani R: Conceptualization, Investigation, Methodology, Project Administration, Writing - Original Draft Preparation, Writing - Review \& Editing; Salazar J: Conceptualization, Investigation, Methodology, Writing - Original Draft Preparation, Writing Review \& Editing; Sharma S: Writing - Original Draft Preparation, Writing - Review \& Editing; Cisneros O: Writing - Original Draft Preparation, Writing - Review \& Editing; Arias-Morales CE: Conceptualization, Investigation, Writing - Original Draft Preparation, Writing - Review \& Editing

Competing interests: No competing interests were disclosed.

Grant information: The author(s) declared that no grants were involved in supporting this work.

Copyright: ( 2021 Rehmani R et al. This is an open access article distributed under the terms of the Creative Commons Attribution License, which permits unrestricted use, distribution, and reproduction in any medium, provided the original work is properly cited.

How to cite this article: Rehmani R, Salazar J, Sharma S et al. COVID-19 associated spontaneous barotrauma: a literature review [version 1; peer review: 2 approved with reservations, 1 not approved] F1000Research 2021, 10:412 https://doi.org/10.12688/f1000research.52381.1

First published: 21 May 2021, 10:412 https://doi.org/10.12688/f1000research.52381.1 


\section{Introduction}

COVID-19 is a disease caused by a novel coronavirus (SARS-CoV-2), which was first identified in December 2019 in Wuhan China. The World Health Organization (WHO) declared the COVID-19 outbreak a Public Health Emergency of International Concern at the end of January 2020 and a pandemic on March 11, 2020. ${ }^{1}$ The presentation of COVID-19 is quite variable, which can involve multiple organ systems, ranging from asymptomatic carriers to severe disease and death. However, over the course of the disease most patients present with fever, chills, cough, and shortness of breath, new loss of taste and/or smell, nausea, vomiting and diarrhea. However, it has been reported that this entity causes mainly respiratory disease. In some severe cases, patients will require endotracheal intubation and mechanical ventilation (MV). Pneumothorax and pneumomediastinum are known complications of MV. However, there have been reports of patients infected with SARS-CoV-2 that have developed pneumothorax, pneumomediastinum or both without any barotrauma. Here, we present a literature review of the potential mechanisms that cause spontaneous pneumothorax and/or pneumomediastinum in COVID-19 patients.

We conducted a comprehensive online literature search using PubMed for articles published with the key words of 'spontaneous pneumothorax', 'pneumomediastinum' and 'COVID-19'. Further references were obtained through crossreferencing the bibliographies cited in each publication.

\section{Background to COVID-19}

The COVID-19 pandemic has changed our world. Scientists identified the novel coronavirus as COVID-19, which was later named severe acute respiratory syndrome coronavirus 2 (SARS-CoV-2). ${ }^{1}$ The WHO had confirmed more than 80,000 cases by the beginning of March 2020 in China and approximately 70 countries around the world were also affected. At the present time, 218 countries and territories across the globe have been infected by the COVID-19 virus. ${ }^{1}$ As of May 2021, the United States leads the world with over 32 million confirmed cases worldwide and over 570,980 deaths currently reported according to the Centers for Disease Control and Prevention (CDC). ${ }^{2}$

The presentation of COVID-19 is variable and can involve multiple organ systems, with patients ranging from asymptomatic carriers to severe disease and death. However, over the course of the disease most patients present with fever, chills, cough, and shortness of breath, new loss of taste and/or smell, nausea, vomiting and diarrhea. The median incubation period time is 4-5 days from the exposure to the onset of symptoms. ${ }^{3}$

\section{Radiologic characteristics of COVID-19}

It has been reported that COVID-19 mainly causes respiratory disease, as observed in a large cohort study in China that included more than 44,000 patients diagnosed with the disease. ${ }^{1}$ As such, it is important to mention some important radiologic characteristics that may aid in the determination of disease severity. Chest radiography findings consist of isolated ground glass opacities, pleural effusion, pneumothorax, pneumomediastinum, and in more advanced disease findings are consistent with severe acute respiratory distress syndrome. ${ }^{4}$ In addition, computed tomography (CT) of the chest serves as an adjunct in diagnosing and assessing the severity of COVID-19, especially when chest x-rays have been reported as normal early in the course of the disease. ${ }^{1} \mathrm{CT}$ chest imaging typically shows nonspecific bilateral peripheral ground glass opacities. ${ }^{5,6}$ This is quite non-specific and can be seen in many different pulmonary diseases for which a detailed clinical assessment is needed. Although CT imaging is of valid clinical utility, CT alone is not recommended nor for screening or diagnosis of COVID-19. ${ }^{5}$

\section{Barotrauma and COVID-19}

As respiratory disease is the most common presentation in patients with COVID-19, in some severe cases, patients require endotracheal intubation and MV. Pneumothorax and pneumomediastinum are known complications of MV. ${ }^{7}$ Figure 1 shows extensive barotrauma with pneumomediastinum and extensive subcutaneous emphysema in a COVID-19 patient on mechanical ventilation who has ground-glass peripheral infiltrates shown both on chest radiograph (CXR) and CT scan. There have been reports of patients infected with SARS-CoV-2 that have developed pneumothorax, pneumomediastinum or both, without any barotrauma. ${ }^{7-9}$

Pneumothorax can be classified into spontaneous, traumatic or iatrogenic. Iatrogenic pneumothorax is most related to MV. ${ }^{10}$ Pneumothorax is rare in intubated patients with normal lungs and most patients with MV associated pneumothorax are reported to have underlying lung diseases (obstructive, interstitial and acute respiratory distress syndrome [ARDS]). ${ }^{11}$ Tension pneumothorax accounts for approximately 30-97\% of all pneumothoraxes in patients with MV. It is important to mention that the presence of pneumothorax has been identified as an independent predictor of mortality in MV with a rate of $46-77 \%$. In addition, it has been associated with increased overall length of hospital stay. ${ }^{10}$ 


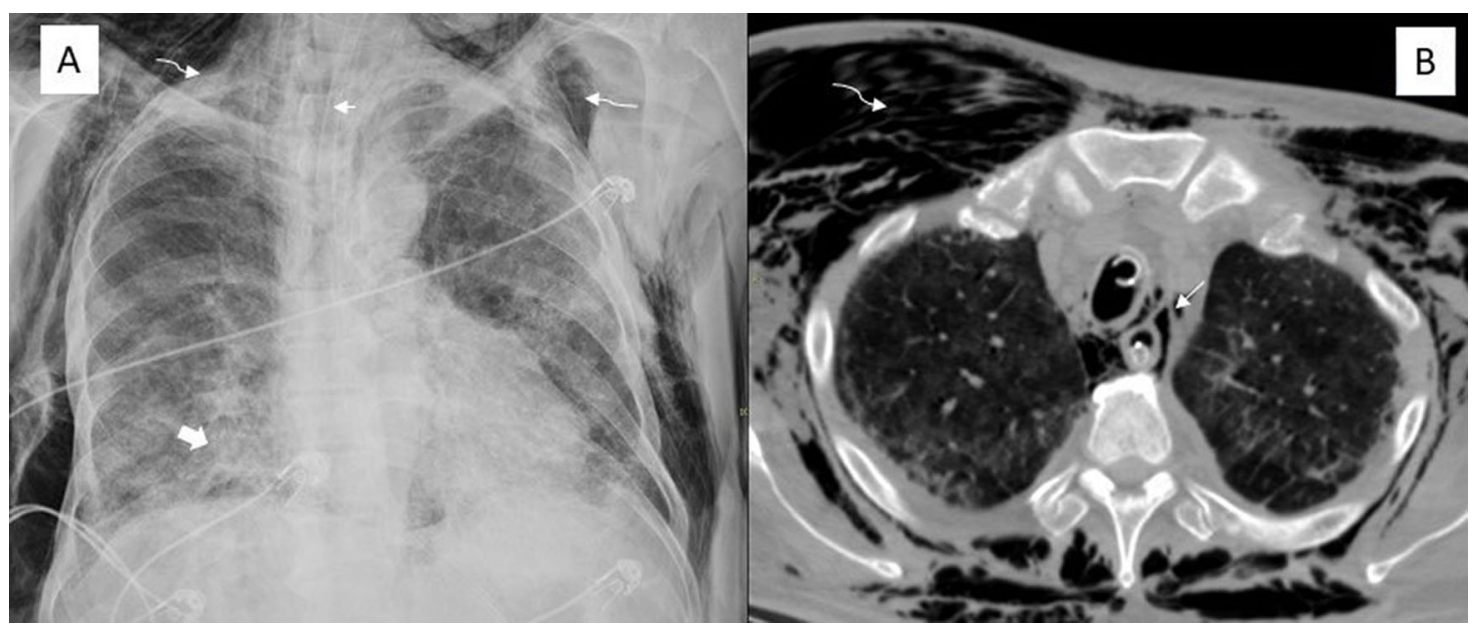

Figure 1. Chest radiograph (A) and axial non-contrast chest CT scan (B) of the chest showing extensive spontaneous pneumomediastinum (straight arrows), extensive bilateral chest wall subcutaneous emphysema (squiggly arrow) and bilateral airspace opacities (solid arrow) suggestive of lung infiltrates.

The classic risk factors for developing spontaneous pneumothorax regardless of COVID-19 status include tobacco smoking, age, short stature, male sex, low body mass index, prolong cough, strenuous exercise and some chronic pulmonary disease such as chronic obstructive pulmonary disease. ${ }^{7}$

The etiology of pneumothorax in COVID-19 is not fully understood. It has been observed in patients with and without MV and, moreover, without significant pulmonary disease burden. The development of spontaneous pneumothorax and pneumomediastinum in COVID-19 patients who do not require MV is rare, and it has been reported in approximately 1-2 \% of patients with COVID- $19^{7}$ vs $5.9-8 \%$ in mechanically ventilated patients, and it can also occur during disease progression. ${ }^{12-14}$ However, if present, it may indicate a worse overall prognosis.

\section{Causes of barotrauma in COVID-19 patients}

The causes of pneumothorax in patients with MV may be related to increased peak airway pressure, high positive end expiratory pressures (PEEP), and high tidal volumes. Figure 2 demonstrates a COVID-19 patient on MV showing extensive pneumomediastinum and resolving pneumothorax post chest tube placement.

Spontaneous barotrauma in the absence of MV is a rare but serious complication in COVID-19 patients, however, the etiology of such barotrauma in the absence of ventilatory support is not completely understood. Some authors report that

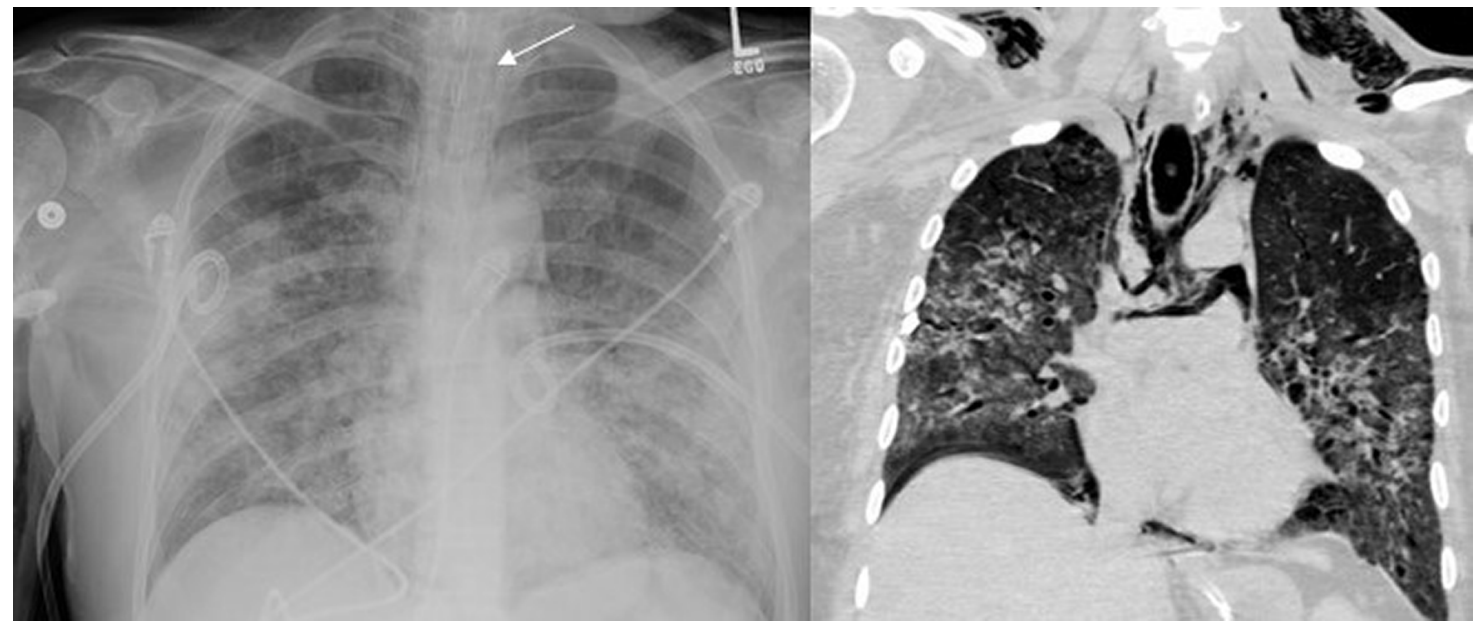

Figure 2. Chest radiograph (left) and coronal non-contrast chest CT scan of the chest (right) demonstrating extensive spontaneous pneumomediastinum (straight arrow) showing extensive pneumomediastinum and resolving pneumothorax post chest tube placement in a COVID 19 patient on mechanical ventilation. 
COVID-19 pneumonia may be associated with severe alveolar damage and rupture of the alveolar wall due to pressure gradient between the alveolus and the pulmonary interstitium. ${ }^{13}$

Another proposed mechanism for the cause of pneumothorax in patients with COVID-19 could be related to direct alveolar membrane damage by the virus infecting pneumocytes I and II, leading to alveolar rupture. ${ }^{15}$ Pathological characteristics of postmortem biopsies of patients who died from SARS-CoV-2 reported pronounced desquamation of pneumocytes and hyaline membrane formation, which are consistent with a diagnosis of ARDS, acute fibrinous pneumonia, and organizing pneumonia. ${ }^{16,17}$

Spontaneous pneumomediastinum has been observed in patients with mild or severe COVID-19 infection even without MV. Figure 3 demonstrates spontaneous pneumomediastinum in a non-mechanically ventilated COVID-19 positive patient, showing peripheral ground glass infiltrates. Chu et al reported cases of patients with confirmed SARS-1 and spontaneous development of pneumomediastinum with and without MV in $2004{ }^{18}$ It is important for clinicians to recognize the development of iatrogenic and spontaneous barotrauma in COVID-19 patients early because it may result in rapid clinical and respiratory deterioration leading to increased oxygen requirements and worsening barotrauma that can be lethal.

\section{Cases of barotrauma in the literature}

Several reports of the development of spontaneous pneumothorax in COVID-19 patients have been published in the literature. Aiolfi et al. ${ }^{19}$ described a case of a 60 -year-old male patient with no previous pulmonary disease and COVID-19 infection that developed right side pneumothorax combined with pneumomediastinum and subcutaneous emphysema after approximately 20 days of the initial infection. He was started on oxygen therapy initially, but the patient failed to improve. A repeat CT demonstrated findings of barotrauma, and subsequently patient was placed on high flow nasal cannula (HFNC) along with steroids, broad spectrum antibiotics and antivirals, without MV. The patient recovered successfully approximately 3 weeks later. In another paper, Changyu et al. ${ }^{20}$ reported a 38-year-old male patient with no past medical history or smoking history admitted for COVID-19 who developed exertional angina with palpitations along with respiratory wheezing on day 11 of admission. CT of the chest revealed multiple ground-glass opacities with bilateral parenchymal consolidations, interlobular septal thickening as well as spontaneous pneumomediastinum and subcutaneous emphysema. The patient was not on MV and continued to receive treatment with supplemental oxygen, antitussives and bronchodilators. By day 25, the patient recovered, symptoms subsided and his breathing returned to normal. Chest CT revealed resolution of previous pneumomediastinum and a reduction of parenchymal consolidation with pulmonary fibrosis and pneumatocele in the inferior left lower lobe. The patient was discharged on day 30 with follow up in the outpatient setting.

Sun et $_{\text {al. }}{ }^{21}$ described a young patient with COVID-19 pneumonia that developed mediastinal emphysema, a giant bulla in the left lung and multiple bullae in the sub pleural lung zones. This patient was not ventilated and placed on HFNC. Patient had no significant relevant medical or smoking history documented. Extensive barotrauma was also reported by Wang et $_{\text {al. }}{ }^{22}$ in a young patient in whom a CT scan of the chest showed pneumatosis extending from the mediastinal pericardium to the bilateral cervical soft tissue space. This patient clinically deteriorated despite immediate noninvasive ventilation and intensive care unit supportive care. In our institution, we also had a 37-year-old patient who was admitted for a second admission for respiratory distress related to COVID-19 infection who developed giant bullae over time in both his lung fields during his hospital stay. Figure 4 shows CXR and coronal chest CT scan of this patient demonstrating

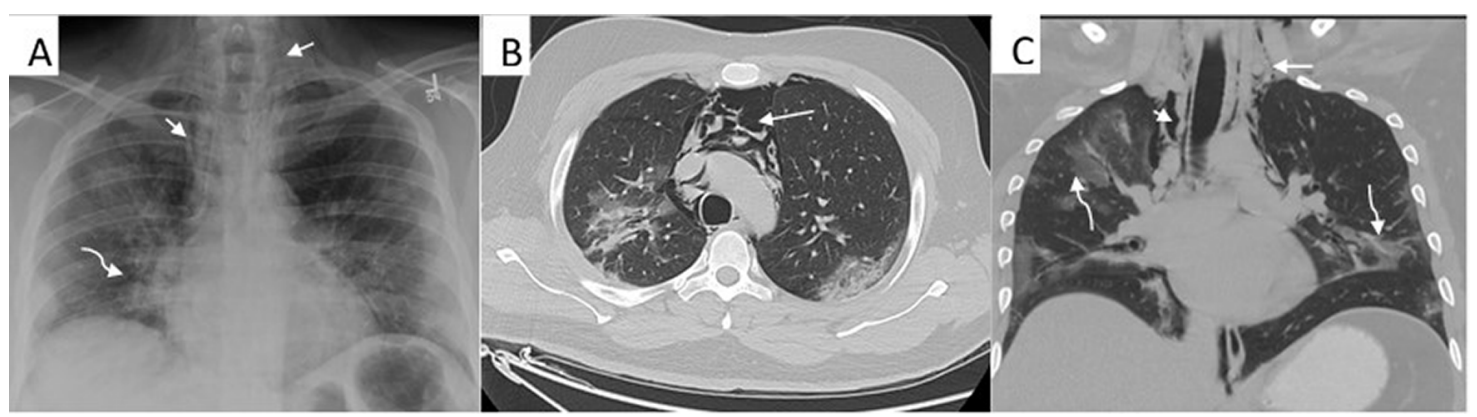

Figure 3. Chest radiograph (A) and axial (B) and coronal (C) reformatted images of a non-contrast CT scan of the chest in a young patient who presented to the emergency room with shortness of breath, showing subtle spontaneous pneumomediastinum (straight arrows) and bilateral airspace opacities suggestive of lung infiltrates. 


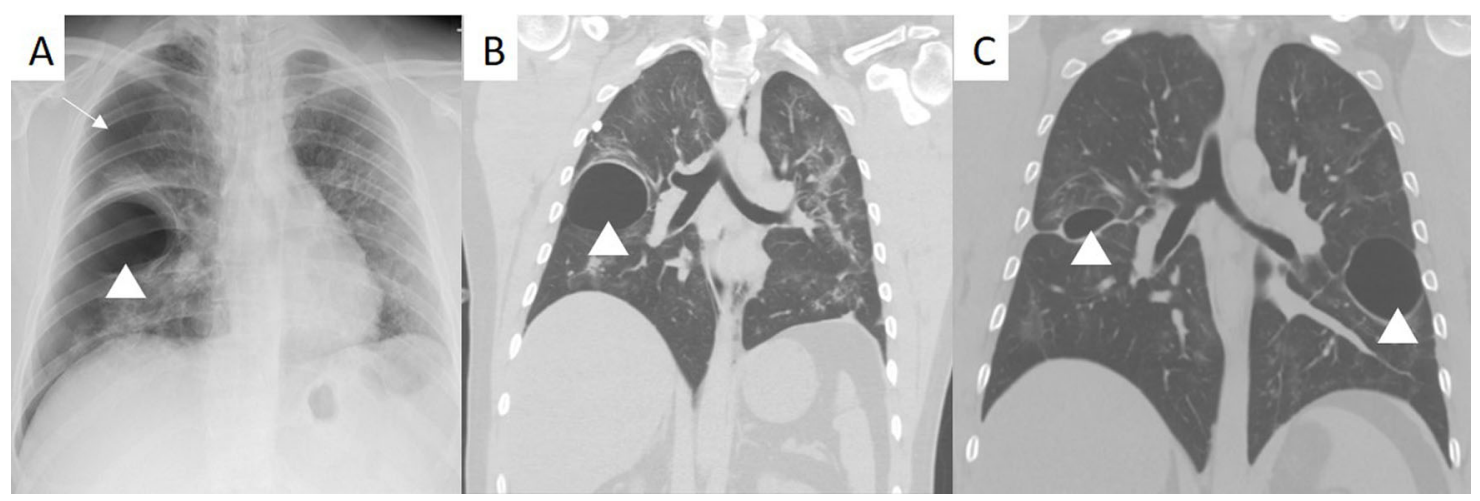

Figure 4. Chest radiograph (A) and coronal view (B) from a chest CT scan showing a large right sided pneumothorax (straight arrow) with a large bullae in the right mid-lung zone (arrowhead) along with patchy bilateral opacities in a patient with recurrent COVID-19 infection who presented to the emergency room with respiratory distress. Coronal Chest CT image (C) obtained one month after discharge showing scarring and decrease in size of the right mid-lung bullae but formation of a second large bulla in the left mid-lung zone.

a large bullae involving the right middle lung zone, which eventually got smaller over the following days but a new bulla appeared in the left lingular region.

In a most recent retrospective study by McGuinness et al. ${ }^{23}$ the authors reviewed clinical and imaging data of patients seen between March 1, 2020, and April 6, 2020, who tested positive for COVID-19 and experienced barotrauma associated with invasive MV and were compared with patients without COVID-19 infection during the same period. A total of 601 patients with COVID-19 infection underwent invasive MV. They reported that $15 \%$ of patients had one or more barotrauma events with a total of 145 barotrauma events (95\% confidence interval [CI]: $21 \%, 28 \%$ ). During the same period, 196 patients without COVID-19 infection with invasive MV had one barotrauma event $(0.5 \%$; $95 \%$ CI: $0 \%$, $3 \% ; P<.001$ vs the group with COVID-19 infection). Of 285 patients with ARDS on invasive MV during the previous four years, $10 \%$ of patients had 31 barotrauma events, with an overall barotrauma rate of $11 \%(95 \% \mathrm{CI}: 8 \%, 15 \% ; P<.001$ vs the group with COVID-19 infection). The authors concluded that patients with COVID-19 infection and invasive MV had a higher rate of barotrauma than patients with ARDS and patients without COVID-19 infection. In addition, barotrauma is an independent risk factor for death in COVID-19 (odds ratio $=2.2 ; P=.03$ ) and is associated with a longer hospital stay (odds ratio $=0.92 ; P<.001$ ).

In contrast, Chung et al. $^{24}$ in a retrospective study from China, reviewed CT chest scans of 21 symptomatic patients infected with COVID-19. Typical CT findings included bilateral ground glass opacities, consolidative pulmonary opacities with variable morphology, notably pneumothorax or pneumomediastinum lesions were not observed. This emphasizes the point that spontaneous barotrauma is not a common but a rare manifestation of COVID-19. The above study was done with only 21 COVID-19 patients and generally lacks the sample size required for a solid assessment of rare but dangerous barotrauma complication.

Pneumothorax is a medical emergency and a disease with a high mortality rate. It requires careful awareness, prompt recognition and immediate intervention to reduce morbidity and mortality. Most patients with pneumothorax related to mechanical ventilation have underlying pulmonary diseases, the most common of which are pneumonia, ARDS and obstructive lung disease. Pneumothorax/pneumomediastinum may have subtle or atypical features on plain radiography and may be missed early on. Most of the ventilated patients with a pneumothorax require immediate treatment with tube thoracostomy because of the high risk of progression to a tension pneumothorax. Small-bore catheters are now preferred in most ventilated patients. Management of non-ventilated barotrauma patient varies case by case but is generally conservative.

In a study by Housman et al. ${ }^{25}$ the authors hypothesized that COVID-19 patients requiring mechanical ventilation may develop significant pneumomediastinum and subcutaneous emphysema without associated pneumothorax. The study included 171 patients who tested positive for COVID-10 requiring endotracheal intubation. They identified 29 cases $(17 \%)$ of mediastinal air without associated pneumothorax that were treated conservatively and 12 cases $(41 \%)$ that showed improvement or resolution without intervention. In another study from Italy by Protti et al. ${ }^{26}$ the authors aimed to describe the incidence and risk factors of barotrauma in patients with COVID-19 on invasive mechanical ventilation. The study was performed via electronic survey and involved patients with COVID-19 who developed barotrauma while 
on invasive mechanical ventilation from 61 hospitals the COVID-19 Lombardy Intensive Care Unit network. Thirtyeight responses were submitted and out of 2041 patients included, about $7.1 \%$ developed barotrauma.

Furthermore, Udi et $a .^{27}$ in their retrospective registry analysis that included 20 patients with severe COVID-19 pulmonary failure found that $40 \%$ of those patients developed severe barotrauma during mechanical ventilation that followed lung protective strategies. Their data suggested that barotrauma in COVID-19 patients may occur despite the use of recommended lung protective mechanical ventilation settings. In addition, data from a retrospective cohort study that included 343 COVID-19 positive patients suggested that these patients have a significant risk of developing barotrauma when receiving invasive mechanical ventilation with subsequent increased mortality rates. The study found that $15.4 \%$ of the patients developed barotrauma and $91 \%$ of these patients presented with pneumothorax, $3.7 \%$ with pneumomediastinum and pneumopericardium. ${ }^{28}$

\section{Conclusion}

Spontaneous pneumothorax and pneumomediastinum are rare, but serious, complications of COVID-19. The most common cause of iatrogenic barotrauma is related to mechanical ventilation in the setting of underlying lung disease, with variable proposed mechanisms ranging from high peak airway pressure, high PEEP and high tidal volume, although none have been proven. Spontaneous barotrauma in COVID-19 in the absence of ventilatory support is presumed to be due to pressure gradient between the alveolus and the pulmonary interstitium due to virus associated alveolar damage. The second mechanism is due to direct alveolar membrane damage leading to its rupture, which could be secondary to direct infection of COVID-19 of the pneumocytes type I and II. This can result in rapid respiratory deterioration with life-threatening consequences if not recognized in time. Pneumothorax associated with mechanical ventilation has more than two-fold increased mortality and this risk increases further in those with tension pneumothorax. Early diagnosis particularly in ventilated patients and immediate treatment with small tube thoracostomy is crucial for a positive outcome.

\section{Data availability}

No data is associated with this article.

\section{Consent}

The images published in this article were retrieved from patient records of patients treated at our institution. We gained IRB approval from our institution (St. Barnabas Hospital IRB; approval number, 2020.23) to use and publish the images in this article, which included a waiver of informed consent from patients. No patient identifiable data is included in the present article.

1. Patel A, Jernigan DB, Abdirizak F: nCoV CDC Response Team. Initial public Heal response interim Clin Guid. 2019.

2. CDC Covid Data Tracker. Reference Source

3. Macera M, De Angelis G, Sagnelli C, et al.: Clinical presentation of COVID-19: case series and review of the literature. Int J Environ Res Public Health. 2020; 17(14): 5062. PubMed Abstract | Publisher Full Text | Free Full Text

4. Ng M-Y, Lee EYP, Yang J, et al.: Imaging profile of the COVID-19 infection: radiologic findings and literature review. Radiol Cardiothorac Imaging. 2020; 2(1): e200034. PubMed Abstract | Publisher Full Text | Free Full Text

5. Plesner LL, Dyrberg E, Hansen IV, et al.: Diagnostic imaging findings in COVID-19. Ugeskr Laeger. 2020; 182(15). PubMed Abstract

6. Brogna B, Bignardi $E$, Salvatore $P$, et al.: Unusual presentations of COVID-19 pneumonia on CT scans with spontaneous pneumomediastinum and loculated pneumothorax: a report of two cases and a review of the literature. Hear Lung. 2020. PubMed Abstract | Publisher Full Text | Free Full Text

7. Quincho-Lopez A, Quincho-Lopez DL, Hurtado-Medina FD: Case Report: Pneumothorax and Pneumomediastinum as Uncommon Complications of COVID-19 Pneumonia-Literature Review. Am J Trop Med Hyg. 2020; 103(3): 1170-1176. PubMed Abstract | Publisher Full Text | Free Full Text

8. Yang $X, Y u Y, X u$ J, et al.: Clinical course and outcomes of critically ill patients with SARS-CoV-2 pneumonia in Wuhan, China: a single-centered, retrospective, observational study. Lancet Respir Med. 2020.

PubMed Abstract | Publisher Full Text | Free Full Text

9. Chen $\mathrm{N}$, Zhou M, Dong X, et al.: Epidemiological and clinical characteristics of 99 cases of 2019 novel coronavirus pneumonia in Wuhan, China: a descriptive study. Lancet. 2020; 395(10223): 507-513.

PubMed Abstract | Publisher Full Text | Free Full Text

10. Hsu C-W, Sun S-F, Lee DL, et al.: Clinical characteristics, hospital outcome and prognostic factors of patients with ventilator-related pneumothorax. Minerva Anestesiol. 2014; 80(1): 29-38. PubMed Abstract

11. Hsu C-W, Sun S-F: Iatrogenic pneumothorax related to mechanical ventilation. World J Crit care Med. 2014; 3(1): 8-14. PubMed Abstract | Publisher Full Text | Free Full Text

12. Yao $W$, Wang $T$, Jiang $B$, et al.: Emergency tracheal intubation in 202 patients with COVID-19 in Wuhan, China: lessons learnt and international expert recommendations. Br J Anaesth, Accept march. 2020; 31. PubMed Abstract | Publisher Full Text | Free Full Text

13. Yamaya T, Baba T, Hagiwara E, et al.: Pneumothorax in a COVID-19 Pneumonia Patient without Underlying Risk Factors. Intern Med. 2020; 59(22): 2921-2925.

PubMed Abstract | Publisher Full Text | Free Full Text

14. Salehi S, Abedi A, Balakrishnan S, et al.: Coronavirus disease 2019 (COVID-19): a systematic review of imaging findings in 
919 patients. Am J Roentgenol. 2020: 1-7. PubMed Abstract | Publisher Full Text

15. Mallick T, Dinesh A, Engdahl R, et al.: CovID-19 Complicated by Spontaneous Pneumothorax. Cureus. 2020; 12(7): e9104-e9104. PubMed Abstract | Publisher Full Text | Free Full Text

16. Copin M-C, Parmentier E, Duburcq T, et al.: Time to consider histologic pattern of lung injury to treat critically ill patients with CoviD-19 infection. Intensive Care Med. 2020: 1-3. PubMed Abstract | Publisher Full Text | Free Full Text

17. Xu Z, Shi L, Wang Y, et al.: Pathological findings of COVID-19 associated with acute respiratory distress syndrome. Lancet Respir Med. 2020; 8(4): 420-422.

PubMed Abstract | Publisher Full Text | Free Full Text

18. Chu CM, Leung YY, Hui JYH, et al.: Spontaneous pneumomediastinum in patients with severe acute respiratory syndrome. Eur Respir J. 2004; 23(6): 802-804. PubMed Abstract | Publisher Full Text

19. Aiolfi A, Biraghi T, Montisci A, et al.: MANAGEMENT OF PERSISTENT PNEUMOTHORAX WITH THORACOSCOPY AND BLEBS RESECTION IN COVID-19 PATIENTS. Ann Thorac Surg. 2020. PubMed Abstract | Publisher Full Text | Free Full Text

20. Zhou C, Gao C, Xie Y, et al.: COVID-19 with spontaneous pneumomediastinum. Lancet Infect Dis. 2020; 20(4): 510. PubMed Abstract | Publisher Full Text | Free Full Text

21. Sun R, Liu H, Wang X: Mediastinal Emphysema, Giant Bulla, and Pneumothorax Developed during the Course of COVID-19 Pneumonia. Korean J Radiol. 2020; 21(5): 541-544. PubMed Abstract | Publisher Full Text | Free Full Text
22. Wang J, Su X, Zhang T, et al.: Spontaneous Pneumomediastinum: A Probable Unusual Complication of Coronavirus Disease 2019 (COVID-19) Pneumonia. Korean J Radiol. 2020; 21(5): 627-628. PubMed Abstract | Publisher Full Text | Free Full Text

23. McGuinness $G$, Zhan C, Rosenberg N, et al.: Increased Incidence of Barotrauma in Patients with COVID-19 on Invasive Mechanical Ventilation. Radiology. 2020; 297(2): E252-E262. PubMed Abstract | Publisher Full Text | Free Full Text

24. Chung $M$, Bernheim $A$, Mei X, et al.: CT imaging features of 2019 novel coronavirus (2019-nCoV). Radiology. 2020; 295(1): 202-207. PubMed Abstract | Publisher Full Text | Free Full Text

25. Housman B, et al.: COVID-19 ventilator barotrauma management: less is more. Annals of Translational Medicine 2020 8(23).

PubMed Abstract | Publisher Full Text | Free Full Text

26. Protti $A$, et al.: Barotrauma in mechanically-ventilated patients with coronavirus disease 2019: a survey of $\mathbf{3 8}$ hospitals in Lombardy, Italy. Minerva Anestesiol. 2020 PubMed Abstract | Publisher Full Text

27. Udi J, et al.: Incidence of barotrauma in patients with COVID-19 pneumonia during prolonged invasive mechanical ventilationa case-control study. J Intensive Care Med. 2021; 36(4): 477-483. PubMed Abstract | Publisher Full Text

28. Elsaaran $\mathrm{H}$, et al.: Prevalence and risk factors of barotrauma in Covid-19 patients admitted to an intensive care unit in Kuwait; a retrospective cohort study. Ann Med Surg. 2021; 63 102141.

PubMed Abstract | Publisher Full Text | Free Full Text 


\section{Open Peer Review}

\section{Current Peer Review Status: $\mathrm{X}$ ? ?}

\section{Version 1}

Reviewer Report 06 December 2021

https://doi.org/10.5256/f1000research.55652.r97971

(C) 2021 Monti G. This is an open access peer review report distributed under the terms of the Creative Commons Attribution License, which permits unrestricted use, distribution, and reproduction in any medium, provided the original work is properly cited.

\section{Giacomo Monti}

Department of Anesthesia and Intensive Care, IRCCS San Raffaele Scientific Institute, Milan, Italy

In this manuscript, Dr. Arias-Morales and colleagues present a narrative review of COVID-19 spontaneous barotrauma. As we are now facing the fourth wave of the COVID-19 pandemic in several countries, this remains an "up-to-date" topic relevant to current practice.

Overall, while the review provides a general cover of most of the relevant aspects related to barotrauma, all topics could be discussed in greater detail. Furthermore, a brief paragraph describing the management of COVID-19-related barotrauma could be useful.

Few lines comparing the rate of barotrauma in COVID-19 vs non-COVID-19 respiratory failure and ARDS might be useful, as there is a general belief of a higher rate of barotrauma in COVID-19 ARDS. In this view, the authors may wish to discuss a recent systematic review on barotrauma in COVID-19 patients (see Belletti et al., 2021 ${ }^{1}$ ).

As a related point, the prognostic impact and risk factors for barotrauma in COVID-19 patients may be worth a discussion in a separate paragraph. Several authors now report higher mortality rates (>60\%) for COVID-19 patients who developed barotrauma.

The authors may also wish to discuss tracheal damage and tracheomalacia associated with COVID-19, which is being increasingly reported and associated with the development of pneumomediastinum (see Guarnieri et al., 20212 ; Fiacchini et al., 202133; Rosati et al., 20214).

Some authors recently described the $\mathrm{CT}$ finding of the Macklin-like effect as a potential predictor of barotrauma in COVID-19 patients (see Palumbo et al., 20215. I believe that these findings could be discussed in the paragraph on possible causes of barotrauma.

It might be useful to add one or more tables summarizing findings of major published studies on barotrauma rate and outcome in spontaneous breathing vs non-invasively ventilated vs invasively ventilated COVID-19 patients.

It might also be useful to add a table summarizing identified risk and predisposing factors 
for barotrauma development in COVID-19 ARDS patients.

A separate paragraph on Methods, describing how the search strategy was performed (last update, keywords, number of reviewers screening articles, etc.) might also be useful.

\section{References}

1. Belletti A, Todaro G, Valsecchi G, Losiggio R, et al.: Barotrauma in Coronavirus Disease 2019

Patients Undergoing Invasive Mechanical Ventilation: A Systematic Literature Review.Crit Care Med. 2021. PubMed Abstract | Publisher Full Text

2. Guarnieri M, Andreoni P, Gay H, Giudici R, et al.: Tracheostomy in Mechanically Ventilated Patients With SARS-CoV-2-ARDS: Focus on Tracheomalacia.Respir Care. 66 (12): 1797-1804 PubMed Abstract | Publisher Full Text

3. Fiacchini G, Tricò D, Ribechini A, Forfori F, et al.: Evaluation of the Incidence and Potential Mechanisms of Tracheal Complications in Patients With COVID-19. JAMA Otolaryngology-Head \& Neck Surgery. 2021; 147 (1). Publisher Full Text

4. Rosati R, De Nardi P, Dell'Acqua A, Calvi M, et al.: Tracheoesophageal Fistula in a COVID-19 Ventilated Patient: A Challenging Therapeutic Decision. Case Reports in Surgery. 2021; 2021: 1-5 Publisher Full Text

5. Palumbo D, Zangrillo A, Belletti A, Guazzarotti G, et al.: A radiological predictor for pneumomediastinum/pneumothorax in COVID-19 ARDS patients.J Crit Care. 66: 14-19 PubMed Abstract | Publisher Full Text

Is the topic of the review discussed comprehensively in the context of the current literature?

Partly

Are all factual statements correct and adequately supported by citations? Partly

Is the review written in accessible language?

Yes

Are the conclusions drawn appropriate in the context of the current research literature? Yes

Competing Interests: No competing interests were disclosed.

Reviewer Expertise: Sepsis and septic shock, non-Invasive ventilation

I confirm that I have read this submission and believe that I have an appropriate level of expertise to confirm that it is of an acceptable scientific standard, however I have significant reservations, as outlined above.

Reviewer Report 08 November 2021

https://doi.org/10.5256/f1000research.55652.r95963 
(C) 2021 Soni K. This is an open access peer review report distributed under the terms of the Creative Commons Attribution License, which permits unrestricted use, distribution, and reproduction in any medium, provided the original work is properly cited.

\section{Kapil Dev Soni}

Department of Intensive and Critical Care, All India Institute of Medical Sciences, New Delhi, India

Rehmani and co-authors reviewed the topic of COVID-19 associated spontaneous barotrauma. They provide a summary of the literature on a relevant problem that is increasingly seen in COVID19 patients. They discuss the common pattern of radiological manifestations seen in these patients. They also mention the common putative mechanisms underlying barotrauma in both mechanically ventilated and spontaneous breathing. The impact on patient outcomes such as increased mortality and morbidity with associated barotrauma has been reported.

However, the review can be further enhanced if the authors discuss the implications of peripherally located lesions and the Macklin Effect seen in COVID-19. They can further discuss the association of the above factors and the development of pneumothorax and pneumomediastinum.

In the Introduction section, the authors provide a succinct introduction about the COVID-19 pandemic, the common presentations, and the varied clinical severity of the patients. They also provide the search strategy used in the selection of articles with keywords, such as "spontaneous pneumothorax and pneumomediastinum" with cross-referencing the bibliographies. However, the keyword "Barotrauma" has not been considered in the search terms. Though the likelihood of the additional article using "Barotrauma" is low, nevertheless authors may attempt a search strategy with some modification.

The authors present the common findings seen on imaging - chest X-ray and CT scan. They mention that CT alone is not recommended for screening or diagnosis of COVID-19, which is an important point as most scientific societies do not recommend using CT scans for the purpose of screening COVID-19. RT-PCR remains the gold standard for diagnosing the infection. It will be useful if the authors provide some details about the timing of HRCT during the course of illness and the prognostic utility of findings seen on the CT chest. Also, the subtle findings which may predict the development of pneumothorax or barotrauma on HRCT in these patients will help readers to identify high-risk patients.

In the following section, the authors provide a description of pneumothorax and pneumomediastinum with extensive subcutaneous emphysema in a patient of COVID-19 on mechanical ventilation. They further discuss the known risk factors of the development of pneumothorax on mechanical ventilation and spontaneous breathing. However, the author's statement: "Tension Pneumothorax accounts for approximately 30-97\% of all pneumothoraxes in patients with MV" needs to be referenced.

The authors discuss the cases of barotrauma and multiple reports published in the literature. The cases provide some perspective about the development of pneumothorax and pneumomediastinum and the evolution of lesions in both mechanically and non-mechanically ventilated patient subgroups. An interesting observation was the development of giant bulla in 
some cases. The authors further cite the studies by McGuinness et al., Chung et al., Housman et al., Protti et al., Udi et al. and provide common patterns of findings of pneumothoraxes, pneumomediastinum, and subcutaneous emphysema. The absence of pneumothorax with substantial pneumomediastinum has also been mentioned. It will be useful for the readers if the authors provide details of the mechanism underlying such unique patterns in the article.

The authors conclude by stating the common cause of iatrogenic barotrauma related to mechanical ventilation with proposed mechanisms in both mechanically and non-mechanically ventilated patients.

The article attempts to provide a literature review of a common complication - barotrauma seen frequently in COVID-19 patients. It is well written with some putative mechanisms underlying the barotrauma. However, it is a narrative review and not a systematic review. The authors do not mention the number of articles retrieved with the search strategy. It's unclear why only one database was searched and not others. Though the objective was to study the mechanisms underlying the barotrauma, no particular mechanism is yet proven and most remain speculative.

Is the topic of the review discussed comprehensively in the context of the current literature?

Partly

Are all factual statements correct and adequately supported by citations? Yes

Is the review written in accessible language?

Yes

Are the conclusions drawn appropriate in the context of the current research literature? Yes

Competing Interests: No competing interests were disclosed.

Reviewer Expertise: Critical Care

I confirm that I have read this submission and believe that I have an appropriate level of expertise to confirm that it is of an acceptable scientific standard, however I have significant reservations, as outlined above.

Reviewer Report 05 October 2021

https://doi.org/10.5256/f1000research.55652.r94554

(C) 2021 Jouvet $P$. This is an open access peer review report distributed under the terms of the Creative Commons Attribution License, which permits unrestricted use, distribution, and reproduction in any medium, provided the original work is properly cited. 


\section{Philippe A. Jouvet}

Department of Pediatrics, Sainte-Justine University Hospital Center, University of Montreal, Montreal, QC, H3T 1C5, Canada

R Rehmani et al. report a literature review on COVID-19 associated spontaneous barotrauma and illustrate the manuscript with several examples including one from their experience. The topic is interesting but the methodology used and the use of spontaneous barotrauma are not adequate in this manuscript.

Major comments:

- A literature review can be a scoping review or a systematic review and the search methodology needs to be detailed in the methodology part of the manuscript to help the reader to understand how the literature review was done. For example, a similar review has been done in 2021 and 36 studies were included ${ }^{1}$. This manuscript does not specify the methodology, has a literature review that included fewer manuscripts than a systematic review published on the same topic, and is restricted to spontaneous barotrauma.

Reviewer does not understand the term 'spontaneous' in this manuscript. Usually, the term 'spontaneous' is used when the condition occurs without an obvious etiology, such as trauma or iatrogenic causes ${ }^{2}$. Mechanical ventilation is a well-known etiology of trauma and the authors included this etiology in the spontaneous. From the reviewer's point of view, any pneumothorax or pneumomediastinum associated with mechanical ventilation should be excluded from a review on spontaneous barotrauma.

Is the topic of the review discussed comprehensively in the context of the current literature? The discussion is not understandable because this manuscript includes spontaneous and nonspontaneous barotrauma under the term spontaneous.

Are the conclusions drawn appropriate in the context of the current research literature? Reviewer does not agree with the conclusions that include, (1) pneumothorax associated with mechanical ventilation in a manuscript on spontaneous barotrauma, and (2) specifies mechanisms that are not demonstrated but are only hypothesised.

\section{References}

1. Agrafiotis AC, Rummens P, Lardinois I: Pneumothorax in otherwise healthy non-intubated patients suffering from COVID-19 pneumonia: a systematic review.J Thorac Dis. 2021; 13 (7): 4519 4529 PubMed Abstract | Publisher Full Text

2. Costumbrado J, Ghassemzadeh S: Spontaneous Pneumothorax. PubMed Abstract

\section{Is the topic of the review discussed comprehensively in the context of the current literature?}

No

Are all factual statements correct and adequately supported by citations? Yes 
Is the review written in accessible language?

Yes

Are the conclusions drawn appropriate in the context of the current research literature? No

Competing Interests: No competing interests were disclosed.

Reviewer Expertise: Critical care medicine

I confirm that I have read this submission and believe that I have an appropriate level of expertise to state that I do not consider it to be of an acceptable scientific standard, for reasons outlined above.

The benefits of publishing with F1000Research:

- Your article is published within days, with no editorial bias

- You can publish traditional articles, null/negative results, case reports, data notes and more

- The peer review process is transparent and collaborative

- Your article is indexed in PubMed after passing peer review

- Dedicated customer support at every stage

For pre-submission enquiries, contact research@f1000.com 